\title{
VILÃO OU VÍTIMA: UMA ANÁLISE DOS ENQUADRAMENTOS DOS PAÍSES NOS CONFLITOS DO GOLFO PÉRSICO NA MÍDIA IMPRESSA BRASILEIRA
}

\author{
Gisela Cardoso Teixeira ${ }^{\mathrm{i}}$
}

Resumo: Este artigo tem como objetivo analisar as representações dos países envolvidos nas Guerras do Irã-Iraque e do Golfo pelos jornais brasileiros. Para isso, serão analisadas as manchetes de capa e excertos de seus respectivos textos do primeiro dia de ambos os conflitos nos impressos Folha de S.Paulo, O Globo e O Estado de S.Paulo, tendo como fundamentação alguns conceitos acerca do enquadramento, das modalidades argumentativas - principalmente em relação à questão dos pontos de vista e ao efeito do pathos na constituição das representações nas manchetes. Com disso, parte-se da hipótese da configuração da imagem de "vilão" ou "vítima" por meio dos enquadramentos midiáticos, que podem ser reconfigurados de acordo com o andamento do contexto das guerras.

Palavras-chave: Jornalismo de guerra. Enquadramento. Argumentação. Representação midiática.

\begin{abstract}
This paper aims to analyze the representation of the countries involved in the Iran-Iraq and the Gulf Wars in Brazilian newspapers. In order to do so, we analyze the cover headlines and the excerpts of their respective texts published on the first day of both conflicts in Folha de S. Paulo, O Globo and O Estado de S. Paulo newspapers. As theoretical background, we draw on the concepts of framing, the argumentative modalities - mainly in relation to points of view and the effect of pathos in the constitution of representations in headlines. Thus, we start from a hypothesis that ties the configuration of the image of "villain" or "victim" to the mediatic frameworks, which can be reconfigured according to the progress of the context of the wars.
\end{abstract}

Keywords: War journalism. Framework. Argumentation. Media representation.

\footnotetext{
' Mestranda em Estudos de Linguagens no Centro Federal de Educação Tecnológica de Minas Gerais (CEFET-MG), Brasil. Bolsista da Capes. E-mail: gisagrind@gmail.com.
} 
EID\&A - Revista Eletrônica de Estudos Integrados em Discurso e Argumentação, Ilhéus, n. 14, jul/dez.2017.

\section{Introdução}

A manchete, seguindo o glossário de jornalismo, "é o título principal que indica a notícia mais importante, [...] é sempre aquela que vier graficamente com maior destaque, o que tiver letras mais carregadas na tinta" (RIBEIRO, 2008, p. 12). Partindo desta definição, as manchetes tem um significativo poder de persuasão, uma vez que "a leitura do texto na íntegra depende da atração que sua manchete exerce sobre o leitor” (MARECO; PASSETTI, 2010, p. 20).

Além de configurar um agendamento', a partir das manchetes já é possível identificar o "recorte" - ou seja, o enquadramento - de um determinado acontecimento, atribuindo identidades e responsabilidades aos atores envolvidos no fato relatado, o que pode ser influenciado pelos critérios de noticiabilidade ${ }^{2}$ e por outros valores ligados a um jogo de intencionalidades em relação ao contexto em que determinado acontecimento emerge. $\mathrm{E}$, durante a cobertura de conflitos armados, é possível observar esse enquadramento aos atores envolvidos, abordando-os ora como "vilões", ora como "vítimas", de acordo com o andamento da guerra em meio a um contexto histórico e político, pois, de acordo com Bakhtin (1988, p. 156), "o contexto que enquadra, lapida os contornos do discurso de outrem como cinzel, entalha uma imagem de língua no empirismo fruto da vida do discurso [...]".

Sendo assim, este artigo tem como objetivo analisar as representações dos países envolvidos nas Guerras do Irã-Iraque e do Golfo pelos jornais brasileiros. Mais especificamente, serão analisadas as manchetes de capa e excertos de seus respectivos textos do primeiro dia de ambos os conflitos nos impressos Folha de S. Paulo, O Globo e O Estado de S. Paulo, tendo como fundamentação alguns conceitos acerca do enquadramento, das modalidades argumentativas - principalmente em relação à questão dos pontos de vista e o efeito do pathos na constituição das representações nas manchetes. Aliás, é importante também analisar os textos que acompanham essas manchetes, a fim de verificar se o enquadramento presente no título é o mesmo identificado no texto da notícia.

\footnotetext{
${ }^{1}$ Também conhecida Agenda-Setting Theory, foi formulada por Maxwell McCombs e Donald Shaw na década de 1970. Defende a ideia de que a mídia determinada quais assuntos farão parte dos diálogos dos consumidores de notícias. Isto é, a mídia diz o que as pessoas devem pensar, como pensar e o que pensar sobre os fatos noticiados.

${ }^{2}$ São o conjunto de valores-notícia que determinam se um acontecimento ou assunto possui potencial para se tornar notícia. Ou seja, de ser julgado como merecedor de ser transformado em matéria noticiável e, por isso, possuindo 'valor-notícia'. Alguns desses valores-notícia estão relacionados, por exemplo, à relevância, à disponibilidade, à proximidade e à atualidade do acontecimento.
} 
EID\&A - Revista Eletrônica de Estudos Integrados em Discurso e Argumentação, Ilhéus, n. 14, jul/dez.2017.

No que se refere ao jornalismo internacional no Brasil, Natali (2003) ressalta que a mídia brasileira ainda depende das informações transmitidas pelas agências de notícias internacionais ${ }^{3}$. Então, é interessante observar se os jornais brasileiros reproduzem os enquadramentos provenientes dos países dessas agências de notícias.

A seleção dos conflitos para a análise se justifica pelo seu impacto na história, especificamente na política e na economia mundiais, uma vez que o petróleo é considerado o principal estopim das guerras no Golfo Pérsico. Logo, é válida uma contextualização histórica de ambos os conflitos - mesmo que seja brevemente -, a fim de observar uma possível interferência do contexto externo nos papéis atribuídos pela mídia aos países envolvidos.

De acordo com Gitlin (1980), o enquadramento é uma questão de seleção, ênfase e exclusão. Essa ideia pode ser relacionada aos conceitos acerca da informação midiática de Charaudeau (2012), que leva em consideração todo o processo comunicacional. Segundo o autor,

[...] comunicar, informar é tudo escolha. Não somente escolha de conteúdos a transmitir, não somente a escolha das formas adequadas para estar de acordo com as normas do bem falar e ter clareza, mas escolha dos efeitos de sentido para influenciar o outro, isto é, no fim das contas, escolha de estratégias discursivas (CHARAUDEAU, 2012, p. 39).

A escolha dos efeitos de sentido para influenciar o destinatário, conforme alega Charaudeau (2012), pode ser relacionada a uma dramatização, a um apelo aos sentimentos do leitor, o que interfere em sua constituição de visão de mundo. Assim sendo, uma análise da argumentação visa observar como um saber partilhado autoriza um discurso persuasivo, além de compreender os elementos dóxicos que fundamentam o discurso e de entender o funcionamento discursivo - isto é, as modalidades sobre as quais se visa a polemizar.

Uma análise a respeito das representações criadas em torno dos países em guerra pode colaborar na compreensão do enquadramento em torno das intencionalidades que regem o contrato de comunicação, pois, de acordo com Thomas Milz (2003), em sua análise sobre a cobertura da mídia alemã da Guerra do Iraque, "quanto mais a câmera focaliza os detalhes, menos vemos o quadro completo. Tão perto e, mesmo assim, tão longe".

\footnotetext{
3 Segundo Natali (2003), a BBC News (Reino Unido), CNN (Estados Unidos) e Reuters AFI (Reino Unido) são algumas das agências de notícias internacionais mais utilizadas como fontes pela mídia brasileira.
} 
EID\&A - Revista Eletrônica de Estudos Integrados em Discurso e Argumentação, Ilhéus, n. 14, jul/dez.2017.

\section{Enquadramentos: conceitos e suas relações com o discurso jornalístico}

Muito se discute a respeito das noções de enquadramento, o que se estende a várias áreas, tais como a psicologia, sociologia e, principalmente, aos campos da comunicação e da linguística. Com isso, Porto (2002, p.1) ressalta que o paradigma acerca do enquadramento "ainda se encontra em estado embrionário". Porém, sua aplicação tem dinamizado o campo da comunicação política, oferecendo uma nova perspectiva para entender 0 papel da mídia.

Ao fazer um retomado de alguns dos principais conceitos e aplicações a respeito do enquadramento, vale ressaltar os estudos realizados por Ervin Goffman, considerado um dos pesquisadores pioneiros em torno do tema.

Em uma abordagem mais sociológica, Goffman (1974) afirma que o enquadramento pode ser visto como marcos interpretativos, construídos no âmbito social, que dão sentido às situações. Em outras palavras, os enquadramentos são princípios de organização que orientam os eventos sociais e a construção de como os indivíduos organizam a experiência.

Eu suponho que as definições de uma situação são construídas de acordo com os princípios de organização que governam os eventos [...] e o nosso envolvimento subjetivo neles; "Enquadrar" é a palavra que eu uso para me referir a esses elementos básicos que eu sou capaz de identificar (GOFFMAN, 1974, p.10).

Já de acordo com Gitlin (1980), o conceito de enquadramento está relacionado a padrões de cognição, interpretação e apresentação, que envolvem a ênfase e a exclusão.

Enquadramentos são princípios de seleção, ênfase e apresentação compostos de pequenas teorias tácitas sobre o que existe, o que acontece e o que é importante. São padrões persistentes de cognição, interpretação e apresentação, de seleção, ênfase e exclusão, através dos quais os detentores de símbolos organizam de forma rotineira o discurso, seja verbal ou visual. (GITLIN, 1980, p. 6-7).

É possível dizer que o enquadramento guia como as pessoas entendem o mundo, e assim, formam julgamentos, conforme também defende Entman (1993, p. 52) em seus estudos.

Enquadrar é selecionar alguns aspectos de uma realidade percebida e torná-los mais salientes em um texto comunicativo, de forma a promover uma definição particular do problema, uma interpretação casual, uma avaliação moral e/ou uma recomendação de tratamento para o item descrito. 
EID\&A - Revista Eletrônica de Estudos Integrados em Discurso e Argumentação, Ilhéus, n. 14, jul/dez.2017.

Aplicando-se mais os conceitos acerca do enquadramento na perspectiva jornalística, é possível dizer que a formação do enquadramento pode ser explicada pela interação de normas e práticas jornalísticas e pela influência de grupos de interesse (SCHEUFELE, 1999).

Logo, certos tipos de interesses, incluindo fontes governamentais, são provavelmente os mais influentes na seleção da agenda e do enquadramento. Porém, para Hackett (1993), a mídia não determina apenas o que as pessoas devem pensar, pois ainda existe um segundo nível de "efeitos da mídia sobre o público".

Sendo assim, o conceito de enquadramento passa a ser visto como instrumento para examinar empiricamente o papel da mídia na construção da hegemonia. Com isso, segundo Porto (2002, p. 24), os “enquadramentos são elementos constitutivos importantes das narrativas e do processo pelo qual fazemos sentido do mundo da política".

Tuchman (1978), por sua vez, defende a ideia de que as notícias impõem um enquadramento que define e constrói a realidade segundo determinadas tipificações. De acordo com o pesquisador, nas palavras de Antunes (2009, p. 89):

[...] os jornalistas produzem tipificações baseados nas ocorrências de eventos que podem se transformar em notícias. Tipificações são classificações com fundamentos em esquemas da prática jornalística. As tipificações, sendo Tuchman, "estão ancoradas ou encaixadas no uso do tempo" e isto produz as notícias como histórias, assim como a ancoragem e o encaixe das tipificações no espaço geram os critérios de noticiabilidade [...].

Seguindo essa perspectiva, Scheufele (1999, p.129) também afirma que "a mídia constrói a realidade social através do enquadramento de imagens da realidade de uma maneira previsível e padronizada”. Com isso, vale ressaltar as questões em torno das intencionalidades, as quais podem ser observadas em alguns vestígios da subjetividade do jornalista e/ou da linha editorial em seus textos. Uma vez que "efeitos de formulação podem ocorrer sem ninguém ter consciência do impacto do enquadramento adotado nas decisões e podem ainda ser explorados para alterar a atratividade relativa das opções. Enquadramentos são, portanto, importantes instrumentos de poder" (PORTO, 2002, p. 5).

Os argumentos defendidos por Porto (2002) podem ser relacionados às ideias de Pestalardo (2006). Segundo o autor, a influência na construção da agenda da mídia e do processo de enquadramento é atenuada em parte pelas 
EID\&A - Revista Eletrônica de Estudos Integrados em Discurso e Argumentação, Ilhéus, n. 14, jul/dez.2017.

preferências dos jornalistas por narrativas dramáticas e pela intervenção do jornalista no lugar onde as notícias ocorrem.

Os enquadramentos - considerando-os como padrões de seleção da realidade - influenciam na seleção do autor pelas narrativas e estratégias discursivas, assim como nos elementos visuais e gráficos de onde se localiza o texto. É possível também observar os enquadramentos, por exemplo, pelos elementos sintáticos (conectivos), pelas metáforas, pela estrutura do texto (características composicionais do gênero, configuração das páginas, etc) e pelos recursos da enunciação.

Por fim, tomando a notícia como um discurso, os acontecimentos passam por um processo de referenciação resultante de seu enquadramento, ao qual se vincula o emprego de estratégias de dramatização e captação 4 .

Retomando então o objetivo desta pesquisa, vale analisar como, por meio dos enquadramentos das manchetes e dos textos dos jornais brasileiros, é possível visualizar uma representação dos países envolvidos nas guerras do Golfo Pérsico em seu primeiro dia, levando em consideração o contexto político e econômico - uma vez que, conforme mencionado, pode haver uma série de fatores (como jogos de poder e interesses) que influenciam na captação e na representação dos acontecimentos no mundo.

2. Enquadramentos em uma dimensão argumentativa: a construção das representações

Ao refletir sobre as noções apresentadas acerca do enquadramento, é possível traçar uma relação com o fato de que todo enunciado determina um ponto de vista sobre o real. Logo, segundo Amossy (2000), todo texto tem uma dimensão argumentativa ${ }^{5}$, em que é possível encontrar determinadas representações dadas aos agentes envolvidos no relato.

Tais representações podem ser associadas ao reforço de determinadas crenças, na medida em que, de acordo com Emediato (2013), as narrativas

\footnotetext{
${ }^{4}$ De acordo com Patrick Charaudeau (2012), a visada de captação se orienta em direção ao parceiro da troca, ao público, a fim de atrair a sua atenção (assim como persuadi-lo) para aquilo que está transmitindo. Sendo assim, serão utilizadas estratégias para atingir esse objetivo como, por exemplo, o uso da dramatização.

${ }^{5}$ Não se deve confundir dimensão argumentativa com visada argumentativa. Para Ruth Amossy, a dimensão argumentativa consiste em transmitir um ponto de vista sobre os fatos, sem que se pretenda expressamente modificar as posições do alocutário. Já a visada argumentativa constitui um fundamento de persuasão sustentado por uma intenção consciente, oferecendo estratégias programadas para sua realização.
} 
EID\&A - Revista Eletrônica de Estudos Integrados em Discurso e Argumentação, Ilhéus, n. 14, jul/dez.2017.

enquadram, roteirizam e categorizam representações hegemônicas, assim como anti-hegemônicas, de acordo com as visadas argumentativas colocadas em jogo. Com isso, aborda-se também o conceito de doxa, considerada como representações partilhadas, como evidências, que permitem considerar um sujeito, sendo que sua intencionalidade é determinada por um conjunto de saberes dos quais ele nem sempre é consciente.

Retomando alguns fundamentos defendidos por Aristóteles, a endoxa poderia ser definida como pontos de acordo estabelecidos pela maioria, pelos homens considerados competentes e autorizados ou pelos sábios, ou seja, representava uma opinião, um conhecimento comum, porém apenas a uma parcela da sociedade. Platão, por sua vez, tratava por doxa uma opinião, um conhecimento comum partilhado pela maioria das pessoas que compõem uma sociedade.

A partir dessa retomada histórica, Amossy (2000) define a doxa como um constructo social, um elemento essencial à argumentação, principalmente como condição de intersubjetividade e, por isso, constitutiva da interação, garantindo a eficácia verbal do discurso - o que pode ser aplicado para analisar e compreender determinados fatos do mundo das notícias.

Charaudeau (2012), por sua vez, lembra que os elementos situacionais também são fundamentais no processo da constituição das notícias. Os papéis sociais ocupados pelos envolvidos em determinado acontecimento podem influenciar, por exemplo, na organização dos textos e nas modalidades que serão utilizadas. Assim sendo, são as intencionalidades (o situacional, presente no processo de transação) que determinarão os enquadramentos e, logo, a organização do texto informativo.

Em relação às visadas argumentativas, é interessante mencionar o poder das emoções presentes nas narrativas, com o intuito de persuadir o leitor. Esse fato se refere ao conceito de pathos, o qual consiste no fenômeno da busca pela emoção. Segundo Charaudeau (2007), o sujeito enunciador ingressa em um processo de dramatização, utilizando argumentos que apelem aos sentimentos e à emoção do sujeito destinatário - ou seja, além de buscar o fazer saber, o enunciador procura despertar o fazer sentir.

Assim sendo, as dimensões e visadas argumentativas - ressaltando a questão da ocorrência de um pathos discursivo ${ }^{6}$ - interferem nas

\footnotetext{
${ }^{6}$ Uma vez que o ethos se refere às características do orador que podem influenciar o processo de persuasão, o pathos diz respeito ao apelo ao lado emocional do público-alvo, enquanto o logos
} 
EID\&A - Revista Eletrônica de Estudos Integrados em Discurso e Argumentação, Ilhéus, n. 14, jul/dez.2017.

representações apresentadas no relato jornalístico, o que pode ser relacionado aos enquadramentos, influenciados pelos diferentes pontos de vista na construção da realidade. Isso também pode ser relacionado aos estudos em torno da noção de ponto de vista (PDV), em respeito à responsabilidade enunciativa. De acordo com Rabatel (2013):

[...] de um modo mais geral, o PDV se define por meios linguísticos através dos quais um sujeito reflete acerca de um objeto, em todos os sentidos do termo refletir, quer o sujeito seja singular ou coletivo. Quanto ao objeto, pode corresponder a um objeto concreto, mas também a um personagem, a uma situação, a uma noção ou a um acontecimento, uma vez em que todos os casos, trata-se de objetos do discurso. O sujeito, responsável pela referenciação do objeto, exprime seu PDV tanto diretamente por comentários explícitos, como indiretamente, pela referenciação, quer dizer, através das escolhas, da combinação, da atualização do material linguístico (RABATEL, 2013, p. 12).

Logo, um PDV pode ser observado por meio dos termos lexicais utilizados (como substantivos, adjetivos, etc), para a criação de uma identificação/representação dos objetos presentes no discurso. Aliás, o enquadramento - que pode ser analisado por meio dos PDVs -, direciona a informação a favor de grupos ou interesses políticos ou econômicos (CHARAUDEAU, 2012, p.64), o que influencia no "recorte" da realidade, do acontecimento, configurando assim o enquadramento das representações presentes no texto midiático.

No caso desta pesquisa, procura-se então analisar a representação dos personagens envolvidos no primeiro dia de dois conflitos no Golfo Pérsico, atentando-se à relação dos enquadramentos com o contexto, o que pode influenciar no processo de referenciação e, logo, refletir os pontos de vistas acerca dos atores responsáveis pelo acontecimento relatado.

\section{Cenário: uma breve contextualização das Guerras Irã-Iraque e do Golfo}

O discurso em si pode ser considerado uma construção linguística atrelada ao contexto social no qual o texto é desenvolvido, conforme afirma Bakhtin (1988). Sendo assim, antes de partir para a análise em si, é importante resgatar alguns fatos dos momentos históricos selecionados - as Guerras IrãIraque e do Golfo - a fim de observar, em seguida, uma possível influência na

trata da argumentação do conteúdo do discurso. Segundo as ideias aristotélicas, esses são os três aspectos fundamentais na persuasão. 
EID\&A - Revista Eletrônica de Estudos Integrados em Discurso e Argumentação, Ilhéus, n. 14, jul/dez.2017.

construção das imagens dos países protagonistas nos conflitos nas manchetes e seus textos nos jornais brasileiros.

O conflito historicamente conhecido como Guerra Irã-Iraque durou oito anos, mais precisamente de 1980 e 1988, envolvendo as duas nações do Oriente Médio, tendo como forte motivação o fundamentalismo religioso e a presença dos Estados Unidos na região (HIRO, 1991, p.32). Mas, já de início, vale mencionar que até o ano de 1979, o Irã era um dos maiores aliados dos estadunidenses na região estratégica, devido ao fato de abrigar a maior parte das reservas mundiais de petróleo. Porém, com a Revolução Islâmica no Irã, o país rompeu relações com os Estados Unidos. Então, para compensar a perda de seu aliado, o governo estadunidense se aproximou do país vizinho, o Iraque, governado por Saddam Hussein, que também temia a expansão do fundamentalismo islâmico do Irã na região.

O conflito se iniciou em 22 de setembro de 1980, quando o Iraque de Saddam Hussein reivindicou a posse do território iraniano de Chatt-el-Arab, um canal que liga o Iraque ao Golfo Pérsico, por meio do qual é escoada a produção petrolífera do país. Após a recusa iraniana, as tropas de Saddam invadiram o Irã e destruíram o que era então a maior refinaria de petróleo do mundo em Abadã. Completamente estagnados, os dois países cessaram fogo em 1988, e não houve vencedores, já que as fronteiras permaneceram as mesmas de antes do conflito. Após a guerra, Saddam não obteve mais o apoio dos Estados Unidos e de outros países árabes (como a Arábia Saudita), já que o Irã não era mais considerado uma ameaça aos seus interesses na região. No entanto, com sua economia abalada, Saddam prosseguiu com sua política agressiva com seus vizinhos, culminando na Guerra do Golfo no início da década de 1990.

Aliás, a Guerra do Golfo começou quando as tropas iraquianas invadiram e anexaram o Kuwait no dia 02 agosto de 1990, após Saddam Hussein acusar o país de prejudicar o comércio de petróleo, vendendo o produto por um preço muito baixo e exigindo também uma indenização, que foi recusada pelo governo kuaitiano. Além disso, Saddam também alegava que estaria restituindo o antigo território de Basra, que era de domínio iraquiano durante a época do Império Turco-Otomano.

A ONU (Organização das Nações Unidas) condenou a invasão e emitiu a ordem de retirada imediata das tropas iraquianas no Kuwait. Porém, com a recusa de Saddam, a ONU permitiu uma interferência militar liderada pelos 
Estados Unidos, formando uma coalização de 34 países (entre eles, Inglaterra, França, Portugal, Espanha, Itália, Egito, Síria e Arábia Saudita). Além do mais, com o Golfo Pérsico fechado, os países ocidentais haviam perdido os seus principais fornecedores de petróleo (FARO, 2008, p.101).

Devido ao intenso ataque da coalização ocidental, o Iraque foi derrotado seis meses após o início do conflito (o cessar fogo foi aceito em abril de 1991) e teve que retirar suas tropas do vizinho Kuwait, além de sofrer um embargo econômico imposto pela ONU. No entanto, Saddam Hussein não foi retirado do poder, e o Iraque não perdeu nenhum de seus territórios originais.

4. A Guerra Irã-Iraque (1980-1988) nos jornais brasileiros: as representações dos países envolvidos

As manchetes, ao apresentar os principais fatos que constituem a narrativa do acontecimento, apontam também uma representação - ou melhor, uma identidade - para os atores envolvidos no fato relatado, atribuindo-lhes uma responsabilidade significativa pela ocorrência de determinado acontecimento.

Em relação ao corpus desta análise, a Folha de S. Paulo noticiou o primeiro dia da Guerra Irã-Iraque por meio da seguinte manchete: Irã decreta bloqueio dos portos do Iraque. Em uma primeira leitura, é possível interpretar que o Irã esteja dando o passo inicial do conflito. Mas apesar do título destacar uma ação do Irã, o texto inicialmente diz que o Iraque realizou duas incursões áreas e bombardeou 16 bases, postos de radar e aeroportos iranianos, inclusive o aeroporto internacional de Teerã. Já a respeito do Irã, é dito que atacou duas bases militares iraquianas, entre elas a de Basra, por onde é escoada grande parte da produção petrolífera do país (inclusive para o Brasil). Sendo assim, mesmo que o Iraque tenha agido primeiro e ter sido mais agressivo (se comparado aos números), na manchete é dada uma ênfase à retaliação iraniana pelo fato de ter atingido a questão do petróleo, o que pode afetar a economia mundial (observa-se que o texto que acompanha a manchete até destaca o Brasil, o que pode criar certa aproximação com seu público-leitor, pois ressalta que a guerra pode atingir seu país de certa forma).

O enquadramento dado ao Irã como o "vilão" no início do conflito pode ser observado mais claramente no segundo parágrafo do texto da manchete. 
EID\&A - Revista Eletrônica de Estudos Integrados em Discurso e Argumentação, Ilhéus, n. 14, jul/dez.2017.

O Estado-Maior iraniano decretou o bloqueio dos portos iraquianos, declarou as suas águas como "zonas de guerra", inclusive o estreito de Ormuz, e anunciou que bombardeará qualquer navio estrangeiro que se dirigir ao Iraque. O governo de Bagdá, por sua vez, advertiu Teerã que "tomará medidas necessárias" para proteger suas exportações petrolíferas?.

Observa-se que, na narrativa, as ações do Irã são colocadas em sequência, principalmente em relação aos verbos selecionados e conjugados no pretérito perfeito ("decretou”, "declarou”, "anunciou”), assim como é colocada a ação do Iraque. No entanto, pode-se perceber um enquadramento mais dramatizado em relação ao Irã, mais especificamente aos termos utilizados para se relacionar ao país - como o uso de "zonas de guerras" entre aspas (o que leva a crer que tenha sido uma declaração direta dos porta-vozes do país), além do anúncio oficial que atacará qualquer navio que se aproximar do país inimigo - o que, em linhas gerais, provoca um pathos, apelando à emoção do leitor para a criação de uma imagem de um país responsável pela guerra. Já em relação ao Iraque, mesmo que "medidas necessárias" estejam também entre aspas, elas não são especificadas, ao contrário do que acontece anteriormente com o Irã. Aliás, vale ressaltar que tais "medidas necessárias" são relacionadas a uma espécie de "bem maior", destinadas a resolver os problemas do petróleo, os quais atingem diretamente a economia mundial.

Já os jornais O Globo e O Estado de S. Paulo, apesar de não apresentar os atores envolvidos já em seu título, enquadram a imagem do Irã da mesma forma, podendo ser interpretado como o responsável pela tensão.

No contra-ataque, aviões Phantom iranianos bombardearam bases áreas iraquianas e o Irã declarou "áreas de guerra" todas as fronteiras marítimas com o Iraque, proibindo "qualquer transporte de mercadoria para os portos iraquianos" e alertando "não se considera responsável pelos cargueiros que se encontrem no Golfo Pérsico e não mudem sua rota depois da travessia do estreito de Ormuz" ${ }^{8}$.

Observa-se que, assim como na manchete da Folha, os verbos selecionados também carregam um respectivo teor de dramaticidade em relação ao seu contexto (como "proibir" e “bombardear”). Aliás, também foram utilizadas, entre aspas, as declarações das autoridades do Irã atribuindo-lhe a responsabilidade pelo o que foi dito - o que contribui ainda mais na criação de sua imagem como "o vilão da guerra".

\footnotetext{
${ }^{7}$ Publicado na Folha de S. Paulo; São Paulo, terça-feira, 23 de setembro de 1980; Ano 59; №. 18.801.

${ }^{8}$ Publicado em O Estado de S. Paulo; São Paulo, terça-feira, 23 de setembro de 1980; Ano 101; №. 32.371.
} 
EID\&A - Revista Eletrônica de Estudos Integrados em Discurso e Argumentação, Ilhéus, n. 14, jul/dez.2017.

Em relação à identificação do Iraque em meio ao acontecimento na guerra, suas ações militares são justificadas no texto - conforme pode ser visto no trecho a seguir - o que causa certa "suavização" na construção de sua imagem em relação ao acontecimento.

O Iraque alegou que os bombardeios de sua aviação foram uma represália a ataques da artilharia iraniana a quatro navios estrangeiros que haviam hasteando iraquiana ao passar pelo estreito de Chatt El-Arab. O Irã afirma que derrubou 11 Migs e suas tropas mataram 244 iraquianos, mas esses números são desmentidos pelo Iraque, que afirma ter imposto grandes baixas aos iranianos e perdido apenas dois aviões ${ }^{9}$.

É curioso observar que, no trecho acima, são mencionados precisamente o número de mortes causadas pelo Irã, enquanto as provocadas e assumidas pelo Iraque não são especificadas, apenas categorizadas como "grandes baixas" - identificando-se, assim, uma espécie de silenciamento, possivelmente a fim de amenizar a ofensiva iraquiana contra o Irã. Em outras palavras, enfatizam-se, então, as informações acerca das ações iranianas.

Sendo assim, a argumentação presente nas manchetes e nos textos não se limita apenas aos termos lexicais selecionados pelo enquadramento dado aos sujeitos do acontecimento, mas também na seleção e exclusão das informações transmitidas nas narrativas.

Por fim, em relação ao contexto geral da Guerra Irã-Iraque, vale lembrar que o Iraque de Saddam Hussein era aliado dos Estados Unidos, enquanto o fundamentalismo islâmico do Irã era tido como uma ameaça aos interesses econômicos do Ocidente no Oriente Médio. Logo, partindo da ideia de que a mídia brasileira ainda dependia das agências de notícias internacionais - sendo a maioria proveniente de países ocidentais -, o enquadramento dado ao Irã e o Iraque nos jornais brasileiros pode refletir o posicionamento político e econômico ocidental - o que, consequentemente, transmite certa hegemonia ideológica.

5. A Guerra do Golfo (1990-1991): o revés no enquadramento da imagem do Iraque

Já na Guerra do Golfo, acontece uma espécie de reviravolta no posicionamento dos países envolvidos no conflito anterior, o que pode

\footnotetext{
9 Publicado em O Estado de S. Paulo; São Paulo, terça-feira, 23 de setembro de 1980; Ano 101; №. 32.371.
} 
EID\&A - Revista Eletrônica de Estudos Integrados em Discurso e Argumentação, Ilhéus, n. 14, jul/dez.2017.

também ser identificado nos enquadramentos nas manchetes e seus respectivos textos noticiosos. Enquanto o Irã, no início da Guerra Irã-Iraque, era enquadrado como aquele responsável pelas ações mais agressivas, na Guerra do Golfo essa imagem passa a ser atribuída ao Iraque, mais especificamente à figura do líder iraquiano Saddam Hussein.

Na manchete Iraque toma Kuait em guerra-relâmpago, da Folha, o verbo "tomar" no presente, enquanto elemento dóxico, transmite um tom de "ofensiva", de "agressividade". Já O Globo apresenta a manchete EUA, URSS, Inglaterra e França punem Iraque por invadir Kuwait, referindo-se ao embargo comercial imposto contra o Iraque (observa-se, aqui, que EUA e URSS, até então dois adversários ideológicos no período da Guerra Fria, se uniram em prol de combater um "inimigo comum" que pode ameaçar a estabilidade mundial). Já O Estado de S. Paulo diz Iraque derruba governo do Kuwait. Aliás, todos os impressos destacam a reação da comunidade internacional, a qual condenou a ofensiva militar do Iraque.

Nesta abordagem, O Globo apresenta um interessante diferencial em relação aos demais impressos analisados: em uma coluna do lado direito da página, há uma imagem do líder iraquiano Saddam Hussein, acompanhada por um breve histórico a seu respeito. Com isso, é interessante observar que no primeiro dia da Guerra Irã-Iraque nem sequer o nome de Hussein é mencionado nas manchetes. Mas, desta vez, é lhe construída uma imagem: Saddam Hussein surge, pela primeira vez, sob a denominação de "ditador", responsável pelo conflito que não só gera instabilidade na região, como também em escala mundial.

Neste caso, o enquadramento dos papéis na guerra não são configurados apenas ao país, mas também à figura de um líder político. Mais exemplos a respeito do uso da dramaticidade - geralmente embasada no "fator choque" e no horror - para a criação da identidade/representação na guerra podem ser vistos nas manchetes: Saddam ameaçou transformar $o$ Iraque e o Kuwait em cemitério para quem "ousar promover uma agressão" contra os dois países (Estado de S. Paulo); O governo iraquiano diz que agiu "em nome de Deus" (Folha de S. Paulo); Saddam Hussein nega retirar tropas do Kuwait (O Globo). Em outras palavras, observa-se um significativo "grau de patemização", uma vez que tais elementos lexicais utilizados atingem as emoções e valores do destinatário (o leitor). 
EID\&A - Revista Eletrônica de Estudos Integrados em Discurso e Argumentação, Ilhéus, n. 14, jul/dez.2017.

Enquanto o Iraque é enquadrado como “o culpado", “o vilão” da guerra, o Kuwait, em contrapartida, recebe um enquadramento direcionado a uma abordagem de "vitimização", uma vez que os textos o retratam como "invadido", "tomado à força” (além do destaque para o número de mortos), com um poder militar significativamente inferior em relação ao Iraque.

O emir (rei) do Kuait, Jaber Al-Ahmad Al-Sabah, fugiu para a Arábia Saudita. Houve de 100 a 300 mortes $^{10}$. (Folha de S. Paulo)

As tropas do Iraque não encontraram nenhuma resistência para cruzar ontem de madrugada a fronteira com o Kuwait, derrubar o governo do emir Saad AAbdullah Al-Sabah e assumir o controle total do país. O emir fugiu de helicóptero para a Arábia Saudita e seu irmão, Fahed Al-Ahmad Al-Sabah, era dado como gravemente ferido. Cerca de 200 kuwaitianos foram mortos ${ }^{11}$. (Estado de $\mathrm{S}$. Paulo)

Enquanto, já no primeiro dia da Guerra Irã-Iraque, o Irã era enquadrado como o responsável pela instabilidade na região e no mundo (em relação ao petróleo), o Iraque acaba por assumir esse papel na representação da Guerra do Golfo - ou seja, houve uma preocupação em enquadrar a figura do Iraque perante o conflito, principalmente o seu líder Saddam Hussein.

É curioso também observar que o discurso utilizado pelas manchetes e textos dos jornais brasileiros não enquadraram o Iraque como "vítima" na Guerra Irã-Iraque, conforme ocorreu com o Kuwait no conflito posterior. No entanto, nos textos jornalísticos, houve uma espécie de justificação às suas ofensivas bélicas, sem o uso de termos e informações que reforçam uma ideia de "julgamento" contra as ações iraquianas.

Então, apesar de um dos atores do acontecimento estar envolvido nos dois conflitos analisados, o seu papel não foi o mesmo, e isso pode ser explicado por meio de uma recontextualização na geopolítica mundial: após a Guerra Irã-Iraque, Saddam Hussein não contava mais com o apoio dos Estados Unidos. Após ocupar uma área estratégica do Kuwait, onde se produzia grandes quantidades de petróleo, acabou atingindo os interesses econômicos ocidentais - o que, mais uma vez, pode ser observado implicitamente nos enquadramentos dos jornais brasileiros.

\footnotetext{
${ }^{10}$ Publicado na Folha de S. Paulo; São Paulo, sexta-feira, 3 de agosto de 1990; Ano 70; №. 22.402.

${ }^{11}$ Publicado em O Estado de S. Paulo; sexta-feira, 3 de agosto de 1990; Ano 111; № 35.419.
} 
EID\&A - Revista Eletrônica de Estudos Integrados em Discurso e Argumentação, Ilhéus, n. 14, jul/dez.2017.

\section{Considerações finais}

Em suma, o contexto político e econômico tem o poder de interferir nos enquadramentos das narrativas, sendo refletido na configuração da identidade dos atores do acontecimento relatado. Logo, a reconfiguração desse contexto (o que envolve, inclusive, certo jogo de interesses) também altera as imagens já construídas anteriormente. Um exemplo desse fato é a imagem estabelecida em torno do Iraque, que protagonizou as duas guerras analisadas, mas assumindo papéis diferentes de acordo com o enquadramento das manchetes e dos textos que as acompanham - que, por sua vez, pode ter sido influenciado pelo posicionamento dos países ocidentais em face das tensões no Oriente Médio.

Nesta pesquisa, foi observado que a representação do Irã, Iraque e Kuwait nos jornais brasileiros foi baseada em uma dramatização e em um apelo aos valores e sentimentos do leitor; que pôde ser analisada por meio dos termos lexicais utilizados. Logo, para criar a imagem de "vilão" ou "vítima", os jornais analisados buscaram provocar o pathos no leitor (um fazer sentir) - seja pela utilização de elementos dóxicos específicos, seja pela seleção, exclusão e ênfase de determinadas informações.

A Folha de S. Paulo, Estado de S. Paulo e O Globo criaram uma espécie de polarização nas identidades dos envolvidos nas Guerras Irã-Iraque e do Golfo: em tempos de conflito, ou se é "vilão" ou "vítima", conforme o enquadramento configurado pela mídia, identificado por meio dos termos utilizados e das narrativas informativas, que possivelmente é influenciado pelo posicionamento dos interesses econômicos e políticos mundiais na região da guerra. Além disso, pode surgir ainda uma terceira imagem: a do "herói", o que pode levar a outra pesquisa com um viés mais aprofundado.

\section{Referências}

AMOSSY, Ruth. L'argumentation dans le discours. Paris: Nathan, 2000.

ANTUNES, Elton. Enquadramento: considerações em torno de perspectivas temporais para a notícia. Revista Galáxia, São Paulo, n. 18, dez. 2009. p. 85-99.

BAKHTIN, Mikhail. Marxismo e filosofia da linguagem. Trad. Michel Lahud e Yara Frateschi Vieira. São Paulo: Hucitec, 1988. 
EID\&A - Revista Eletrônica de Estudos Integrados em Discurso e Argumentação, Ilhéus, n. 14, jul/dez.2017.

CHARAUDEAU, Patrick. As estratégias de encenação da informação. In: Discurso das mídias. São Paulo: Contexto, 2012. p. 127-174.

. Pathos e Discurso Político. In: MACHADO, Ida L.; MENEZES, William; MENDES, Emilia (Org.). As emoções no discurso. Rio de Janeiro: Lucerna, 2007.

EMEDIATO, Wander. A construção da opinião na mídia: argumentação e dimensão argumentativa. In: Emediato, Wander. (Org). A construção da opinião na mídia. Belo Horizonte: NAD, 2013. p. 69-103.

ENTMAN, Robert Mathew. Framing: toward clarification of a fractured paradigma. Journal of Communication, New York, v.43, n.4, 1993. p.51-58.

FARO, Miguel Coldron de Tovar. A Guerra do Golfo de 1991. Trabalho de Investigação Aplicada - Academia Militar, Lisboa. 2008. Disponível em http://comum.rcaap.pt/handle/10400.26/6982. Acesso em: 30 mai. 2017.

GITLIN, Todd. The whole world is watching: mass media and the making and unmaking of the new left. Berkeley: University of California, 1980.

GOFFMAN, Erving. Frame analysis. Nova York: Harper \& Row, 1974.

HACKETT, Robert. Declínio de um paradigma? A parcialidade e a objetividade nos estudos dos media noticiosos. In: TRAQUINA, Nelson (Org.). Jornalismo: questões, teorias e "estórias". Lisboa: Vega, 1993. p. 101-130.

HIRO, Dilip. The Longest War: The Iran-Iraq Military Conflict. New York: Routledge, 1991.

MARECO, Raquel Tiemi Masuda; PASSETTI, Maria Célia Cortez. Greve dos professores do Estado de São Paulo: Efeitos de (im)parcialidade em manchetes de dois jornais paulistas. Revista NUPEM, Campo Mourão, v.2, n. 3, ago./dez. 2010. Disponível em http://www.fecilcam.br/revista/index.php/nupem/article/view/106/85. Acesso em: 17 jun. 2017.

MILZ, Thomas. Longe demais, perto demais: a Guerra do Iraque e a mídia alemã. In: GOYZUETA, Verónica; OGIER, Thierry (Org.). Guerra e Imprensa: um olhar crítico da cobertura da Guerra do Iraque. São Paulo: Summus, 2003.

NATALI, José Batista. Jornalismo Internacional. São Paulo: Contexto, 2003.

PESTALARDO, Maria. War on The Media: The News Framing of the Iraqi War in the United States, Europe and Latin America. Johnson City: East Tennessee State University, 2006.

PORTO, Mauro P. Enquadramentos da mídia e política. In: ALBINO, Antonio; RUBIM, Antonio Albino Canelas (Orgs.). Comunicação e política: conceitos e abordagens. São Paulo: Unesp, 2002. 
EID\&A - Revista Eletrônica de Estudos Integrados em Discurso e Argumentação, Ilhéus, n. 14, jul/dez.2017.

RABATEL, Alain. O papel do enunciador na construção interacional dos pontos de vista. In: Emediato, Wander. (Org). A construção da opinião na mídia. Belo Horizonte: NAD, 2013. p. 19-66.

RIBEIRO, Maria Rosane. Glossário de jornalismo. 2008. Disponível em: oglobo.globo.com/quemle/Programa/glossario_de_jornalismo.doc. Acesso em: 17 jun. 2017.

SCHEUFELE, Dietram A. Framing as a theory of media effects. Journal of Communication, New York, v.49, n.1, mar. 1999. p.103-122

TUCHMAN, Gaye. Making news: a study in the construction of reality. New York: The Free Press, 1978.

Forma de citação sugerida:

TEIXEIRA, Gisela Cardoso. Vilão ou vítima: uma análise dos enquadramentos dos países nos conflitos do Golfo Pérsico na mídia impressa brasileira. EID\&A - Revista Eletrônica de Estudos Integrados em Discurso e Argumentação, Ilhéus, n. 14, p. 6682, jul/dez.2017.

Recebido em: 03/09/2017

Aprovado em: 27/11/2017 